\title{
DIFICULDADES NO ENSINO E NA APRENDIZAGEM DE QUÍMICA ORGÂNICA DO ENSINO SUPERIOR - ESTUDO DE CASO EM DUAS UNIVERSIDADES FEDERAIS
}

\author{
Natália Bozzetto Alves ${ }^{\mathrm{a}, *, \odot}$, Fábio André Sangiogo ${ }^{\mathrm{a}, \odot}$ e Bruno dos Santos Pastoriza ${ }^{\mathrm{a}, \odot}$ \\ aCentro de Ciências Químicas, Farmacêuticas e de Alimentos, Universidade Federal de Pelotas, 96010-900 Capão do Leão - RS, \\ Brasil
}

Recebido em 26/08/2020; aceito em 15/12/2020; publicado na web em 22/01/2021

\begin{abstract}
DIFFICULTIES IN TEACHING AND LEARNING ORGANIC CHEMISTRY IN HIGHER EDUCATION - A CASE STUDY IN TWO FEDERAL UNIVERSITIES. This research investigates difficulties associated to the curricular component Organic Chemistry I based on a study case of Chemistry undergraduate courses (Bachelor and Teachers education) in two Federal Universities in the Brazilian South region. The analytical process integrated official documents of the courses (pedagogic projects, students' grades), questionnaires, interviews, and researcher's logbook of classes. Results show that the students' success in Organic Chemistry I is lower than the sum of failure, unattendance, and temporary cancellation rates altogether in the curricular component offered by the different teachers and institutions studied. A complex scenario is highlighted in relation to factors that affect learning and teaching processes in undergraduate Organic Chemistry courses. The subjects' responses highlight difficulties related to specific contents, such as conformation and spatial visualization of molecules, stereochemistry, and reaction mechanisms; lack of concepts from High School; and individual habits and characteristics of teachers, students, or both, such as didactics, concentration, and engagement. The results report on the importance of rethinking strategies and methodologies in the context of Organic Chemistry I in Higher Education.
\end{abstract}

Keywords: higher education; chemistry undergraduate courses; organic chemistry; teaching and learning.

\section{INTRODUÇÃo}

Assumindo que a Educação em Química se constitui como uma área formada numa comunidade que sobre esse campo atua e pesquisa nos diversos níveis educacionais, ${ }^{1}$ evidencia-se que essa área tem dentre seus propósitos a formação integral dos sujeitos como eixo de desenvolvimento. Tal assumpção coloca em questão a interação social e cultural no processo de formação de pessoas (e profissionais) que tenham a capacidade de buscar o conhecimento além da Química. ${ }^{2}$ Nesse sentido, evidencia-se que a Educação em Química, partindo da área básica sobre a qual trabalha, a Química, propõe a existência de uma ciência que vai muito além de teorias e experimentos, mas que transforma vidas. ${ }^{3}$

Ainda que a Química esteja presente de modo marcante na sociedade atual, como integrada em medicamentos, vestuário, alimentação, combustíveis, geração de energia, tecnologia, meio ambiente e com efeitos para a economia, ${ }^{2}$ não se observa que a utilização de tais artefatos ou construtos seja mediada por um conhecimento químico apropriado e que permita aos sujeitos o entendimento das mudanças que essa área mobiliza na sociedade. ${ }^{4}$

Se, por um lado, a ciência Química se caracteriza por sua dinâmica e avanços tecnológicos muito significativos nos últimos anos, ${ }^{5}$ por outro, muitas atividades relacionadas aos processos de ensino formal da Química ainda têm como característica a apresentação de aulas expositivas, com foco na memorização de conceitos que não estão relacionados ao contexto dos indivíduos que deles participam. ${ }^{3,6}$ Essa dissonância tende a indicar à área de Educação em Química que há a necessidade de maior articulação, aprofundamento e realização de estudos relacionados, por exemplo, a diferentes abordagens teórico-metodológicas envolvendo práticas docentes em aulas de Química, ${ }^{7,8}$ a fim de minimizar tal distanciamento e, principalmente, mitigar as dificuldades de compreensão e apropriação dessa área pelos sujeitos.

*e-mail: natalia.bozzetto@gmail.com
No que tange às dificuldades no ensino da Química, estudos apontam que suas características de ser um campo abstrato e que, portanto, dificulta a inter-relação entre conceitos provenientes do cotidiano e os conceitos provenientes da Ciência que são ensinados na escola são os principais limitadores de sua compreensão., ${ }^{910} \mathrm{De}$ modo geral, a palavra "dificuldade remete a obstáculos, barreiras ou impedimentos, com que alguém se depara ao tentar realizar atividades que podem ser relacionadas ao aprendizado de cada indivíduo em todas as áreas do conhecimento". ${ }^{11}$ Nesse sentido, dificuldades de ensino e de aprendizagem estão presentes da Educação Básica à PósGraduação, sendo que para a presente pesquisa tais elementos são importantes de se pensar quando relacionados à Química.

Não é de hoje que a área de Ensino de Química busca novas metodologias e abordagens com perspectivas construtivistas que valorizam a mediação entre professor e estudantes, a fim de superar o ensino meramente tradicional ${ }^{12-15} \mathrm{e}$ assim reduzir as dificuldades $\mathrm{e}$ obstáculos apresentados por professores e estudantes. Nesse cenário, investigações referentes às dificuldades de aprender e de ensinar Química, seja em geral, seja em algum de seus subcampos ou níveis de atuação em específico, têm ganhado destaque no seio da comunidade de Educação em Química. Particularmente, como ponto interessado desta pesquisa, destacam-se as produções relativas à aprendizagem e ao ensino na área da Química Orgânica, especialmente no nível do Ensino Superior. ${ }^{16-18}$ Nessas pesquisas, evidencia-se que as dificuldades ou lacunas no aprendizado dos estudantes do Ensino Superior vêm causando altos índices de reprovação, algumas vezes com reprovações sucessivas, e que tendem a causar a evasão e a retenção nos cursos de Química e, portanto, precisam ser mais

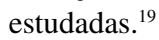

Segundo Roque e Silva, ${ }^{18}$ a área da Química Orgânica ainda é pouco investigada no Ensino Superior. Como indicado pelas pesquisas, nos currículos de formação superior em Química, em disciplinas de Química Orgânica básica, há tópicos com uma variedade de conceitos que apresentam problemas de aprendizagem entre os estudantes universitários. ${ }^{17,18,20}$ As dificuldades de aprendizado 
tendem a estar ligadas à falta de vínculo entre Química Orgânica e outros conceitos químicos, como a falta de contextualização com o cotidiano dos estudantes, além de dificuldades na interpretação da linguagem química. . $^{18,21,22}$

Os problemas provenientes do complexo processo de ensino e de aprendizagem implicam, consequentemente, nos índices elevados de reprovação e desinteresse de estudantes com o aprender e de professores com o ensinar. ${ }^{23}$ Dentre várias opções com vistas à superação das dificuldades de aprendizagem em Química e, especificamente, em Química Orgânica, têm-se desde propostas da utilização de artigos científicos como recurso didático, ${ }^{24}$ do uso da experimentação utilizando materiais do cotidiano, ${ }^{25}$ até a busca de novas abordagens didáticas ${ }^{16,26}$ para a melhoria da percepção dos estudantes, como, por exemplo, de ferramentas capazes de facilitar a visualização desse universo que, sistematicamente, opera num nível bidimensional (entre quadros, cadernos e projeções) para se falar em um espaço de fenômenos tridimensionais. ${ }^{27}$

Ao considerar o exposto, o problema da presente pesquisa se fundamenta no interesse de contribuir com processos de ensino e de aprendizagem que estejam associados a uma das disciplinas que possuem conceitos basilares para a formação de um profissional da área da Química (seja bacharel ou licenciado), bem como ao fato da Química Orgânica I (QO I) possuir altos índices de reprovação e evasão no Ensino Superior evidenciadas no contexto de estudo. Para isso, assume como espaço de desenvolvimento o estudo de caso realizado em cursos de Bacharelado e Licenciatura em Química de duas Universidades Federais do sul do Brasil. Nesse contexto, os resultados contribuem com o mapeamento de diferentes dificuldades citadas por discentes e docentes no contexto da Química Orgânica I, entre essas: a falta de uma base conceitual proveniente do Ensino Médio; a necessidade de atenção para o ensino e a aprendizagem associada com conformações e visualização das moléculas em 3D e de conteúdos como estereoquímica e mecanismos de reação; e a presença de hábitos e características de docentes e/ou discentes. $\mathrm{O}$ cenário da pesquisa apresenta a complexidade de fatores que interferem nos processos de ensino e de aprendizagem de Química Orgânica no Ensino Superior, o que viabiliza (re)pensar possibilidades de sua minimização ou superação.

\section{METODOLOGIA}

O recorte temporal da pesquisa contempla graduandos matriculados de 2016/1 a 2019/2 no componente curricular de Química Orgânica I (QOI) para os Cursos de Química (Bacharelado, Industrial e Licenciatura) da Universidade Federal de Pelotas (UFPel) e de Química Licenciatura da Universidade Federal do Pampa (Unipampa - Campus Bagé). Desse modo, com base no registro das folhas de notas, totalizam 409 estudantes matriculados: 316 na UFPel; e 93 na Unipampa. Esse recorte temporal se deve por entender que esses alunos estariam ainda no Curso, haja vista que os cursos têm duração de 4 anos, facilitando o contato via e-mail ou presencial. Após, realizou-se o envio dos questionários por via eletrônica e presencial foram obtidas 52 respostas discentes.

Os questionários utilizados para produção de dados foram realizados de modo presencial e online, com o objetivo principal de abranger o maior número de discentes das duas Universidades. Aos estudantes matriculados no ano de 2019, presentes no componente de QOI, o questionário foi realizado presencialmente em suporte físico, sendo que para os discentes que não estavam em aula (matriculados nos anos anteriores) houve utilização do suporte digital propiciado pelo sistema Google Forms ${ }^{\circledR}$. O questionário continha 19 questões com perguntas abertas, fechadas e com escala de mensuração tipo Likert (conforme documento suplementar em apêndice), e foi elaborado com o objetivo de reconhecer perfil dos estudantes e avaliar o contexto da QOI dos Cursos. Assim como os estudantes, os docentes da área de Química Orgânica da UFPel e Unipampa também foram convidados a participar da pesquisa, por meio de entrevistas semiestruturadas ou respondendo o questionário via e-mail, composto por 14 questões (apêndice), conforme preferência de cada um dos professores. As questões foram elaboradas com o objetivo de que os docentes pudessem se expressar sobre as disciplinas de Química Orgânica, as dificuldades percebidas nos estudantes e as que encontram ao ministrar as suas aulas, entre outras.

Os professores selecionados são aqueles que atuam em disciplinas de QOI e Química Orgânica II (QOII), nos cursos de Química da UFPel e Unipampa, para que pudessem expor as percepções sobre o ensino e o aprendizado dos conteúdos dessas disciplinas. A seleção dos professores de QOII se deve por entender que eles também podem identificar dificuldades de aprendizagem e de ensino que estejam associadas a conceitos que fazem parte da QOI. No total, são sete docentes da área de Química Orgânica da UFPel e três da Unipampa, dos quais quatro docentes da UFPel e dois da Unipampa responderam as questões. Entre os docentes participantes, três responderam as questões de maneira eletrônica e três presencialmente. Nas atividades de respostas presenciais, realizadas no formato de entrevistas, elas foram gravadas e transcritas.

Nas duas Universidades foi solicitado junto às coordenações de curso e aos professores de QOI o acompanhamento de algumas aulas, a fim de buscar possíveis fatores que contribuam para as dificuldades de aprendizado. Em uma das Universidades não foi possível realizar o acompanhamento das aulas, enquanto na outra Universidade não houve impedimento pelo docente responsável pela turma em questão, sendo acompanhados alguns encontros. No acompanhamento foi utilizado um diário de bordo para a produção dos dados. ${ }^{28}$ Essa estratégia implica em registros que compõem um instrumento reflexivo de atividades e que pode ser utilizado como material de análise do processo de ensino e aprendizagem a partir da técnica de observação, descrição, análise e reflexão do que foi observado. Nesse sentido, o diário de bordo pode ser utilizado ainda como um instrumento complementar durante a pesquisa, pois a partir dele podem ser coletados dados como o contexto em que a pesquisa é desenvolvida e sobre os sujeitos envolvidos. ${ }^{28}$

Os participantes da pesquisa (estudantes e professores) tiveram liberdade para participar ou não das atividades de produção de dados, havendo uso dos dados dos estudantes que aceitaram e responderam ao Termo de Consentimento Livre e Esclarecido utilizado na investigação.

Os dados, originados a partir de entrevistas, questionários a discentes e docentes e de diário de bordo de aulas assistidas, foram tratados por meio da Análise de Conteúdo. ${ }^{29}$ Bardin define a análise de conteúdo como um conjunto de instrumentos metodológicos em constante aperfeiçoamento. ${ }^{29}$ Segundo Moraes,${ }^{30}$ ela constitui uma metodologia de pesquisa usada para descrever e interpretar o conteúdo de toda classe de documentos e textos, permitindo ao autor ter várias interpretações sobre o que está sendo analisado.

$\mathrm{Na}$ análise de conteúdo, Moraes ${ }^{30}$ aponta três fases como fundamentais: i) Pré-análise; ii) Exploração do Material; e iii) Tratamento dos Resultados. A Pré-análise é definida como a fase da organização do material que será útil à pesquisa, enquanto na Exploração do Material passa por uma descrição e análise de maneira aprofundada. Segundo Bardin, ${ }^{29}$ após cumprir a segunda fase o pesquisador deve classificar o material, categorizando-os de acordo com a pesquisa. Além de identificar unidades de registro, o autor passa a codificar e categorizar. Na última fase, de Tratamento dos Resultados, define-se qual será o corpus da pesquisa, ou seja, o conjunto de documentos que serão submetidos à análise - realizada por 
inferências e interpretações, ou seja, é quando a análise se materializa, com análise reflexiva. ${ }^{29}$

Para cada um dos componentes de QOI em investigação foram gerados códigos das unidades de análise para a garantia do anonimato dos participantes durante a pesquisa. ${ }^{30}$ Os códigos utilizados foram: U1 ou U2, para as Universidades integrantes da investigação; QL, para indicação de discentes do curso de Química Licenciatura, QB, para Química Bacharelado, e QI, para Química Industrial. Uma vez que as turmas investigadas poderiam conter discentes de cursos além desses três citados, pois, no caso da UFPel, eram turmas abertas para outros cursos, tais discentes foram mapeados e suas unidades identificadas a partir de seus cursos, sendo assumidos os códigos QF, para Química Forense, e F, para Farmácia. As falas indicadas com $\mathrm{P}$ são referentes aos docentes. Os números $1,2,3, \ldots$ foram utilizados para indicar cada sujeito ou instituição. QOI foi utilizado para o componente curricular de Química Orgânica I e QOII para Química Orgânica II. A tipologia do material analisado também foi codificada, como, para Diário de Bordo, DB, para as Entrevistas, E, e para os Questionários, Q. Por exemplo, o código U2/QL1/Q se refere a uma das Universidades, ao sujeito 1 do curso Química Licenciatura, com fragmento de dados do Questionário; e E-U1/P3/QOII, que se refere ao respondido na entrevista com o professor 3, de Química Orgânica II, de uma das Universidades.

As atividades da presente pesquisa e seu estudo de caso possibilitaram, a partir da análise de conteúdo, a construção de duas categorias emergentes: "Obstáculos e dificuldades no processo de ensinar e aprender Química Orgânica" e "O papel dos docentes e discentes na melhoria do aproveitamento de Química Orgânica: estratégias e possibilidades". Neste texto, a apresentação dos resultados discute a primeira categoria. $\mathrm{Na}$ sequência, de modo a tornar viável a compreensão do caso estudado, são apresentados elementos básicos de contextualização.

\section{O ESTUDO DE CASO: BASES E CONTEXTO DA PESQUISA}

Pela perspectiva teórica adotada nesta pesquisa, o Estudo de $\mathrm{Caso}^{31}$ é uma metodologia de construção da pesquisa que assume que a escolha do "caso" precisa ser expressiva e representativa, tendo a capacidade de fundamentar situações análogas que possam surgir. ${ }^{32}$ Nesse sentido, o estudo de caso tem como uma de suas características a articulação com instrumentos de pesquisa tais como fontes documentais, entrevistas, observações, entre outras. ${ }^{32}$ No âmbito educacional, o estudo de caso possibilita aproximar o pesquisador do seu "objeto de estudo", ${ }^{33}$ e pode seguir três fases: i) delineamento da pesquisa, definição e destaque a aspectos relevantes que vão surgindo ao decorrer da pesquisa; ii) diversificação de fontes e métodos de coletas, instrumentos e procedimentos; iii) ética por parte do pesquisador, que precisa demonstrar todos os caminhos percorridos durante a pesquisa, ou seja, descrever de forma detalhada todos os procedimentos realizados..$^{33} \mathrm{O}$ estudo de caso vai além de uma escolha metodológica específica, pois passa a ser a escolha do que será estudado, uma vez que o conhecimento gerado por ele será diferenciado em relação a outros métodos de pesquisa, tornando-o mais contextualizado. ${ }^{34}$

No caso da nossa investigação, analisam-se dois contextos institucionais, a UFPel e a Unipampa -Campus Bagé, mais especificadamente um grupo de estudantes que cursam ou cursaram Química Orgânica I (QOI) e de professores envolvidos nos componentes curriculares de QOI e Química Orgânica II (QOII), por entender que esses sujeitos trazem respostas à questão das dificuldades associadas ao processo de ensino e aprendizagem de Química Orgânica no Ensino Superior.
O problema da pesquisa se fundamenta no interesse de contribuir com processos de ensino e de aprendizagem que estejam associados a uma das disciplinas que possuem conceitos basilares para a formação de um profissional da área da Química (seja bacharel ou licenciado). Além disso, esse problema também se associa ao fato da disciplina de QOI possuir altos índices de reprovação e evasão em Cursos de Química, segundo levantamento preliminar realizado nos Cursos de Química Bacharelado, Industrial e Licenciatura da UFPel e do curso de Química Licenciatura da Unipampa (Campus Bagé). A escolha das instituições tem relação com espaço de formação de um dos autores do trabalho.

O acesso aos Projetos Pedagógicos dos Cursos de Química Licenciatura da Unipampa e de Química Licenciatura e Bacharelado em Química da UFPel possibilitou a evidenciação de semelhanças nas estruturas dos cursos das duas instituições: ambos estão divididos em Componentes Curriculares Básicos e Profissionais; preveem a flexibilização curricular, haja visto o atendimento a diretrizes nacionais; as disciplinas têm regime semestral e a ascensão no curso obedece a pré-requisitos para a progressão da matrícula dos estudantes ao decorrer da formação.

O componente curricular de QOI é ofertado em períodos distintos nas duas Universidades, e possui pré-requisitos diferentes. Na UFPel, nos cursos investigados, a disciplina é ofertada no segundo semestre e precisa obter aproveitamento satisfatório em "Química Geral" (QG) e "Química Geral Experimental" (QGE). Na Unipampa, até a mudança da grade curricular do curso, o único quesito para cursar a disciplina de QOI era a aprovação em QG. No entanto, no período de realização da pesquisa, alterações levaram a oferta da QOI para o terceiro semestre, trazendo como pré-requisito a disciplina de Química Inorgânica I, a qual tem como pré-requisito a Química Geral I (QGI).

Ao analisar os conceitos da "Química Geral", percebe-se que eles estão reunidos em um semestre na UFPel e divididos em dois semestres na Unipampa. Na ementa da Unipampa, estudantes já começam a ter algum contato com os conceitos relacionados à Química Orgânica I a partir do primeiro semestre, em QGI, como no estudo do conceito de funções orgânicas, ligações químicas e interações intermoleculares. Na UFPel, essa relação mais estreita com a QOI será ainda na disciplina de QG a partir de conteúdos de ligações químicas e de interações intermoleculares. Cabe também a observação de que as aulas experimentais desenvolvidas no âmbito da Química Geral e Experimental da UFPel, bem como nas de Química Geral (I e II) da Unipampa (que têm divisão em aulas teóricas e práticas), há conceitos associados com a Química Orgânica, como processos de separação de misturas e propriedades químicas de determinadas substâncias. No entanto, a relação entre essas diferentes áreas da própria Química não está evidente na ementa das duas instituições e Cursos de Química investigados. Ainda, no caso da Unipampa e UFPel, nota-se que Química Inorgânica I reforça conteúdos associados a ligações químicas covalentes e ao estudo das propriedades químicas da matéria. Na Unipampa, há novamente o estudo das interações intermoleculares em Química Inorgânica I, o que pode dar subsídios importantes à construção de conceitos da QOI.

Nos cursos de Química (Bacharelado, Industrial e Licenciatura) da UFPel, a QOI possui uma carga horária de 60 horas por semestre. A oferta possui uma rotatividade entre dois professores, e as turmas são mistas (como citado, integram a turma discentes de outros cursos, como Química Forense e Farmácia), o que pode inviabilizar articulações e relações mais próximas ao campo específico de atuação profissional. Nesses cursos, a QOI tem como objetivo geral de ministrar ao aluno conhecimentos teóricos para a compreensão dos processos e transformações que envolvam as diversas classes de compostos orgânicos e a inter-relação com o cotidiano. Segundo 
os dados do Projeto Pedagógico de Curso da Licenciatura em Química da UFPel, os objetivos específicos são: “ministrar ao aluno conhecimentos sobre nomenclatura, estrutura conformacional e espacial, bem como as principais reações envolvendo alcanos, alcenos, alcinos e compostos aromáticos", sendo que a ementa compreende: "estudo do átomo de carbono e funções orgânicas, análise corformacional e isomeria espacial, reações de adição eletrofílica dos alcenos e alcinos, reações de compostos aromáticos e reações radicalares". 35

Na Unipampa, a QOI é ofertada somente para o curso de Química Licenciatura. Essa alteração é recente, haja visto que até o ano de 2016 a oferta era realizada em conjunto com os demais cursos da instituição que apresentavam essa disciplina em sua grade curricular. A QOI é ministrada pelo mesmo professor, em todas as últimas edições de oferta, sendo a caracterização dessa disciplina exclusiva ao curso de Química Licenciatura. A QOI possui uma carga horária de 60h e possui como objetivos: "descrever e reconhecer funções orgânicas e seus representantes mais importantes, relacionando suas estruturas com as propriedades físicas e químicas, bem como os métodos de obtenção além de estudar a adaptação do conteúdo do componente curricular para a apresentação no ensino médio e ainda compreender os mecanismos de reações orgânicas, além de realizar rodas de conversa e seminários sobre o conteúdo apresentado". ${ }^{36}$ A ementa compreende: "estudo da estrutura dos compostos orgânicos, isomeria estequiométrica, reatividade química ácida e básica, propriedades físicas e químicas das funções orgânicas, introdução a mecanismos de reações orgânicas, além de transposição didática das funções orgânicas utilizando abordagens de temas". ${ }^{36}$

As informações que estão apresentadas nos projetos pedagógicos referentes ao componente curricular QOI permitem a identificação de algumas semelhanças nas duas Universidades, em conceitos trabalhados durante o semestre, por exemplo, estrutura dos compostos orgânicos, funções, reações de adição, isomeria, mecanismos. Alguns conceitos como acidez e basicidade dos compostos são vistos somente na Química Licenciatura da Unipampa, bem como a utilização de uma metodologia que contempla "a transposição didática das funções orgânicas a partir da utilização de temas”.

Diante do exposto, percebe-se um enfoque distinto na QOI: na UFPel se busca formar profissionais da área da química, podendo ser eles Bacharéis em Química, Químicos Industriais e Químicos Licenciados; na Unipampa os objetivos e ementa são específicos à formação de professores de Química. Na organização das aulas, segundo informações dos Plano de Ensino das duas Instituições de Ensino Superior (IES), predomina a menção para aulas expositivas e dialogadas, com resolução de exercícios e a utilização de provas e trabalhos como método de avaliação. No entanto, a Unipampa, pelo enfoque na formação de professores, destaca a adaptação de conceitos químicos para serem trabalhados no ensino médio, fazendo o uso de seminários e de rodas de conversa.

$\mathrm{Na}$ UFPel, a QOI é ofertada por dois professores (P1 e P2), as turmas variaram de 18 a 43 estudantes, e são compostas por turmas mistas, dos cursos de Química (Bacharelado, Forense, Industrial, Licenciatura) e Farmácia. Na Unipampa, a QOI é ofertada por um professor (P1), as turmas variam de 15 a 32 estudantes matriculados e todos estes são do Curso de Química Licenciatura.

Dos 52 estudantes da UFPel e da Unipampa que responderam ao questionário, a distribuição corresponde aos Cursos de: Química Bacharelado 6 (12\%), Industrial 9 (17\%) e Licenciatura $12(23 \%)$ da UFPel e do curso de Química Licenciatura 18 (35\%) da Unipampa. Ainda, participaram 7 (13\%) alunos do curso de Farmácia da UFPel, já que as turmas de QOI são mistas e aceitam matrículas de outros Cursos. De todos discentes, $77 \%$ são oriundos de instituições públicas de ensino, sendo 30 (58\%) de escolas Estaduais, 8 (15\%) de Municipais e $2(3,8 \%)$ de Federais, enquanto 12 (23\%) são de instituições privadas.

Diante do exposto, com base na apresentação do contexto das duas IES e do componente curricular de QOI, evidencia-se a complexidade do cenário de pesquisa que perpassa os sujeitos envolvidos (professores ou estudantes). Isso motivou a busca por dados sobre o aproveitamento discente nessa disciplina e a elaboração de instrumentos e de procedimentos de produção de dados que possibilitassem uma análise sobre as dificuldades associadas a esse componente curricular.

\section{A PERCEPÇÃO DA DIFICULDADE EM QUÍMICA ORGÂNICA NO ENSINO SUPERIOR}

Sobre as dificuldades com o processo de ensino, os professores, que foram entrevistados de maneira presencial ou que responderam as questões via e-mail, fazem alguns registros quando questionados sobre quais eram as dificuldades ou obstáculos encontrados ao ministrar a disciplina de Química Orgânica:

O maior obstáculo dos alunos vem do ensino médio, com uma base de conhecimento muito fraca em Química Orgânica. (E-U1/P5/QOII);

O maior obstáculo, que não seria um obstáculo e sim uma adequação, eu creio que é que os alunos hoje não estão nivelados. Então, tem um desnível de formação e conhecimento por falta de base. (E-U1/P3/QII)

O poder público precisa dinamizar isso, melhorar a educação básica, o ensino médio. (E- U1/P4/QOII).

As aulas, na Educação Básica e no Ensino Superior, muitas vezes, tendem a focar na memorização de conceitos e de reações químicas, provocando uma falsa ideia de aprendizagem da Química, além de tornar a Ciência pouco atraente, pois se aprende para a prova, não se fazem associações dos conteúdos com o contexto, com conceitos entre si e com conceitos já estudados ${ }^{37}$ Em consequência, há impressão de que os alunos não estudaram determinados conteúdos. Os conceitos Químicos que estão inseridos nos currículos do Ensino Médio, tradicionalmente, são considerados pelos estudantes como abstratos e de difícil compreensão. ${ }^{9,38} \mathrm{O}$ modelo de ensino também pode ser associado com a formação inicial e continuada dos professores, pois muitas das lacunas que os estudantes apresentam durante o componente curricular são "heranças" de seus professores, com práticas docentes de estudo e de ensino balizadas em uma experiência vivida que se reproduz, independendo do (in)sucesso.

Nesse contexto, é necessário que os docentes tenham discernimento para entender que muitas das dificuldades de aprendizagem estão associadas a outros fatores e não são de responsabilidade exclusiva dos discentes. ${ }^{22,38}$ Nesse sentido, as falhas e o fracasso escolar no Ensino Superior, para além da responsabilidade dos estudantes ou da formação anterior, também devem ser associados a outros fatores, como o contexto institucional, aspectos sociais e econômicos. ${ }^{39}$ Pereira e colaboradores ${ }^{39}$ com base no estudo realizado em uma universidade federal, destacam o desempenho acadêmico como a variável mais importante na permanência dos discentes no Ensino Superior, seguidos de fatores ligados ao ambiente institucional, as características pessoais e anteriores ao ingresso, e ao contexto familiar e condições financeiras do estudante. Nesse sentido, pesquisadores ${ }^{19,39}$ defendem medidas de acolhimento e de acompanhamento para ajudar os alunos ingressantes na integração aluno-universidade e aluno-professor, tendo em vista os diversos fatores associados com a permanência na universidade, a exemplo dos altos índices de reprovação nos primeiros semestres. Portanto, faz-se necessária uma preparação da universidade 
e dos docentes para atender, em especial, as turmas iniciais, a fim de minimizar esses índices de evasão e para que os estudantes tenham melhores condições para uma formação profissional de qualidade.

A percepção sobre o motivo, as hipóteses ou consequências práticas sobre a dificuldade dos estudantes também pode ser representada pela fala de um dos docentes: "Bom, com relação às dificuldades, aqui eu vou citar, por exemplo, a formação anterior deles, quando eles chegam na universidade, pelo fato da química orgânica ser lá no final do ensino médio. Tem vezes que eles não veem com profundidade esse conteúdo e chegam não reconhecendo até cadeias carbônicas ou nomenclaturas de compostos normais" (E-U1/P5/QOII).

P5 ressalta dificuldades que identifica ao ensinar a Química Orgânica (QO) do Ensino Superior, o que está relacionado com lacunas do Ensino Médio que, por vezes, não trabalha com a QO, interferindo diretamente no desempenho acadêmico dos estudantes no Curso. Os conceitos iniciais de QO, como o de reconhecer cadeias carbônicas, quando são vistos no Ensino Médio, muitas vezes estão baseados apenas na memorização de funções orgânicas, os grupos funcionais, sendo rapidamente esquecidos, pois não entenderam propriedades químicas que lhes são características. ${ }^{40,41}$ Além disso, os estudantes, podem ter dificuldades em tópicos considerados básicos, não conseguindo visualizar ou imaginar moléculas simples ou grupos funcionais. ${ }^{21}$ Por isso, aprender QO pode ser uma tarefa mais árdua para alguns, e a busca por ferramentas para tornar os conceitos mais atrativos pode ser uma alternativa viável. Tais movimentos podem auxiliar na minimização de lacunas conceituais oriundas do Ensino Médio, assim como nas relações entre conceitos e o cotidiano, que viabilizam os processos de construção de conceitos ensinados. ${ }^{10,41}$

Além da discussão que reporta para a formação da educação básica dos estudantes, os professores acrescentam outros elementos importantes a serem considerados e que refletem nos índices de aproveitamento dos componentes curriculares de QO:

Entre as dificuldades eu acho que falta estudo também! Falta eles reconhecerem qual é a limitação deles e irem atrás. Certo? Porque a Orgânica I é básica, muitos conteúdos repetem, mas eles não estudam (E-U2/P1/QOI);

São várias dificuldades/obstáculos. Primeiro a base de formação insuficiente, a falta de "brio", de vontade e objetivos dos alunos. A falta do hábito de estudar e a falta de intimidade com os livros (agravado pelo uso da internet) (E- U1/P1/QOI); Primeiro a concentração... Os estudantes de hoje em dia estão muito desmotivados, dispersos, ficam muito ligados no celular e nas redes sociais. Eles ficam muito conectados em sala de aula. Eles não têm paciência de certa forma para ficarem sentados em uma sala de aula escutando o que o professor tem para passar para eles. Não ficam em aula (E-U1/P3/QOII); Outro problema é a questão da distração hoje. Hoje em aula, assim, eles estão muito distraídos. Eles têm muito acesso a celular e etc. Ou seja, tem várias coisas que fazem com que estejam presentes, mas as vezes não de "espírito" (E-U1/ P5/QOII);

Eles têm o grau de atenção muito diminuído. É muita distração... O celular é uma máquina que para sala de aula ainda é prejudicial (E-U2/P1/QOI);

$\mathrm{O}$ crescimento da tecnologia das redes sociais faz com que o aluno perca um pouco o foco do estudo. Uma pena, pois a tecnologia de hoje nos permite acesso ao conhecimento rapidamente, quando usada corretamente (E-U1/P1/QOI);

Outro fator que contribui para as dificuldades, conforme os docentes das duas universidades, está relacionado com a autonomia, atitudes e/ou hábitos dos discentes. O conceito de autonomia está relacionado a distintos contextos, tais como: políticos, econômicos e educacionais. Segundo Schnetzler e Aragão, ${ }^{42}$ a autonomia dos estudantes nas aulas de Química está diretamente relacionada ao processo de ensinar e aprender. Independentemente do nível de ensino, aprender pode ser um processo complexo, pois cada estudante vai responder de uma maneira. Nessa perspectiva, a formação na Educação Superior pode ser considerada um processo de múltiplas faces, nas quais os docentes e os discentes têm autonomia em seus atos e, ainda assim, estão envolvidos de tal maneira que a interação entre estes indivíduos é fundamental durante o processo de ensino e de aprendizagem.

Ainda que os fatores assinalados pelos docentes tenham uma relação maior com uma "concepção" deles sobre o aproveitamento discente, do que uma posição efetivamente organizada a partir de dados e estudos sobre o tema do aproveitamento, é possível assumir que as relações que eles acenam merecem atenção e discussão, uma vez que estão imbricadas no processo formativo discente. Sobre tais aspectos, alguns estudos ${ }^{37,39,43}$ propõem discussões que podem se articular com as compreensões desses docentes. Complementarmente, os relatos ratificam estudos de Alvarenga e Sales, ${ }^{23}$ que entendem que nos últimos anos os docentes têm se deparado, cada vez mais, com estudantes que chegam ao Ensino Superior despreparados e com baixo nível intelectual, oriundos de uma formação deficitária na educação básica, além de jovens constantemente conectados, distraídos e dispersos. Nesse sentido, P3, P5 e P1 chamam a atenção para a falta de concentração dos estudantes e distração além da constante utilização do celular em sala de aula.

Matta e colaboradores ${ }^{44}$ ainda ressaltam que a autonomia dos estudantes na universidade tem se tornado um obstáculo para o aluno e para o professor, pois os estudantes não vêm apresentando um bom rendimento acadêmico e os professores já se sentem desmotivados. Nesse sentido, essas pesquisas encontram eco com as falas docentes, pois, segundo P2: “Assim como são variados os alunos, também são variados os motivos das dificuldades, mas em geral se referem a uma base fraca do ensino médio, a falta de maturidade e de objetivos concretos e ao fato de não terem o hábito de estudo" (E-U2/P2/ $\mathrm{QOI})$. Isso acaba repercutindo nas atitudes docentes, no contexto da QO: “O professor também se sente desestimulado quando olha para a turma e vê alunos estudando outras disciplinas, usando o celular, etc.” (E-U2/P2/QOII).

Na concepção dos docentes, entre as dificuldades e obstáculos para a aprendizagem, está a "falta" de hábitos, como o estudo dos discentes. Entre as técnicas que podem ser utilizadas para diminuir o insucesso dos estudantes em QOI está a orientação de atividades de estudo para melhorar a compreensão dos conceitos abordados em aula, conforme apontam pesquisas na área de Ensino. ${ }^{44,45}$ Nesse conjunto de investigações sobre o sucesso na formação em Ensino Superior, evidencia-se que muitos discentes chegam a esse nível sem o hábito de estudar e, muitas vezes, sem saber estudar, enquanto outros alegam estudar e, ainda assim, não conseguem os requisitos para a aprovação. ${ }^{44}$

Dessas pesquisas é possível observar sua relação com os sujeitos participantes do estudo. Os estudantes, ao serem questionados sobre os hábitos de estudo em QOI, apresentam dados que ratificam, em parte, as falas de alguns professores e investigações citadas. Dos 52 estudantes que responderam ao questionário: 23 (44\%) dizem estudar durante o semestre; 17 (33\%) estudam somente para as provas; e $12(23 \%)$ somente quando sobra tempo. O P5 destaca que "para ter um aproveitamento positivo no componente curricular é necessário muito estudo, pois é difícil; os conteúdos são prérequisitos para vários outros conceitos importantes" (E-U1/P5/ QOII). Nesse sentido, reforça-se a importância que professores 
que atuam nos primeiros semestres dos Cursos têm em ajudar na orientação e acolhimento sobre a sistemática da universidade ${ }^{19} \mathrm{e}$ dos estudos, de modo que a autonomia tenha resultado positivo no processo de aprendizagem.

Ainda, sobre a dificuldade do Curso de graduação que escolheram e o componente curricular de QOI, ao solicitar que estudantes indicassem seu grau de dificuldade em uma escala de 0 a 10, tipo Likert (sendo atribuído 0 a extremamente fácil e 10 a extremamente difícil). Os resultados reportam para a dificuldade com o Curso e com a QOI, conforme Figuras 1 e 2.

Os estudantes que participaram da pesquisa classificam o Curso ao qual pertencem com dificuldade de média até extremamente difícil, com média de 7,65 e desvio padrão de 1,03. No caso da QOI (Figura 2), obteve-se média de 6,42 e desvio padrão de 1,83, na classificação do grau de dificuldade da disciplina. Esses indicadores tendem a refletir no índice de aproveitamento em QOI.

No questionário foi solicitado que graduandos expressassem se já reprovaram e quantas vezes reprovaram em QOI, havendo as seguintes indicações: 23 nunca reprovaram; 18 reprovaram uma vez; 07 duas vezes; 3 três vezes; e 1 quatro vezes. Observa-se que mais da metade dos graduandos que respondeu ao questionário já reprovou pelo menos uma vez no componente curricular.

Ao analisar as folhas de notas e o aproveitamento discente, dos matriculados em QOI (Quadro 1), percebe-se uma taxa de reprovação e infrequência que são superiores à taxa de apovação, o que converge para a percepção da dificuldade com a QOI no Ensino Superior.

Ao analisar o aproveitamento em QOI dos diferentes professores, observam-se índices de aprovação mais baixos que a soma dos índices de reprovação e infrequência, o que permite a percepção de uma dificuldade de aprovação em QOI que independente do grupo de estudantes matriculados, professores ( $\mathrm{P} 1$ ou $\mathrm{P} 2$ ) ou instituição (U1 ou U2). Também cabe destacar que, mesmo em turmas com alunos de apenas um Curso, como é o caso da U2, os dados apontam elevados índices de reprovação, infrequência e evasão (trancamentos e cancelamentos) em QOI.

Nesse sentido, a realidade e os dados das IES investigadas indicam a existência de dificuldades de ensino e de aprendizagem em QOI do Ensino Superior, onde são formados bacharéis e licenciados em Química, como podem ser percebidas as aprovações e reprovações do Quadro 1. Diante do exposto, corroboram-se as ideias de Valadão e colaboradores ${ }^{46}$ de que o ensino de Química Orgânica está em "crise", mesmo com a gama de recursos disponíveis como: simuladores, softwares, recursos visuais, livros entre outros.

As universidades brasileiras passaram por transformações a partir da criação de programas como: o Programa de Apoio a Planos de Reestruturação e Expansão das Universidades Federais (REUNI) em 2007 e o Sistema de Seleção Unificada (SISU) 2009/2010, a partir das notas obtidas no Exame Nacional do Ensino Médio (ENEM), facilitando o ingresso dos estudantes no Ensino Superior. ${ }^{47}$ Segundo Jesus, ${ }^{9}$ esses Programas, simultaneamente com o aumento no número de vagas nas IES, fizeram com que os índices de evasão, de abandono parcial ou total dos cursos pelos estudantes, também fossem elevados.

Os índices de retenção e evasão são maiores nos cursos de Bacharelado em Química e Química Licenciatura em função das dificuldades de aprendizagem, segundo dados obtidos a partir do censo da Educação Superior em 2016 realizado pelo Instituto Nacional de Pesquisas Educacionais Anísio Teixeira (INEP). ${ }^{48}$ A título de exemplo, a evasão nos cursos de Química Licenciatura chegou a valores superiores a $50 \% .{ }^{48}$ Segundo Yamaguchi e colaboradores, ${ }^{49} \mathrm{O}$ motivo está relacionado aos índices de reprovação e à permanência dos

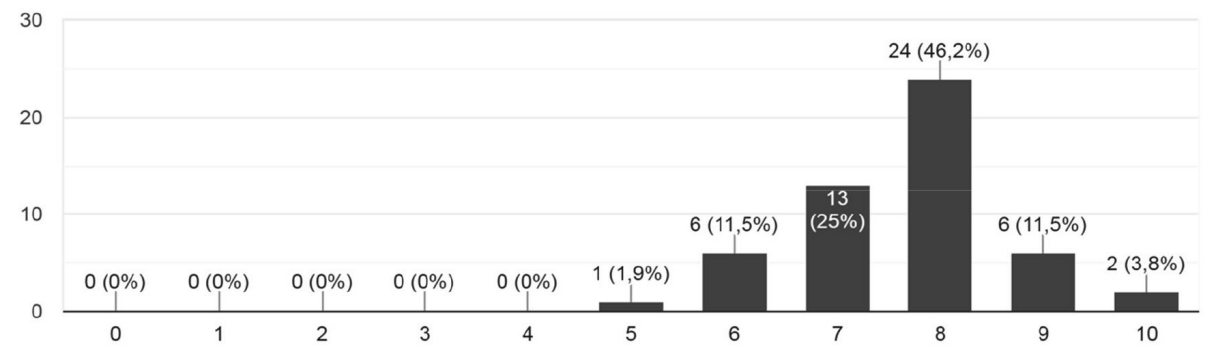

Figura 1. Grau de dificuldade do curso de graduação

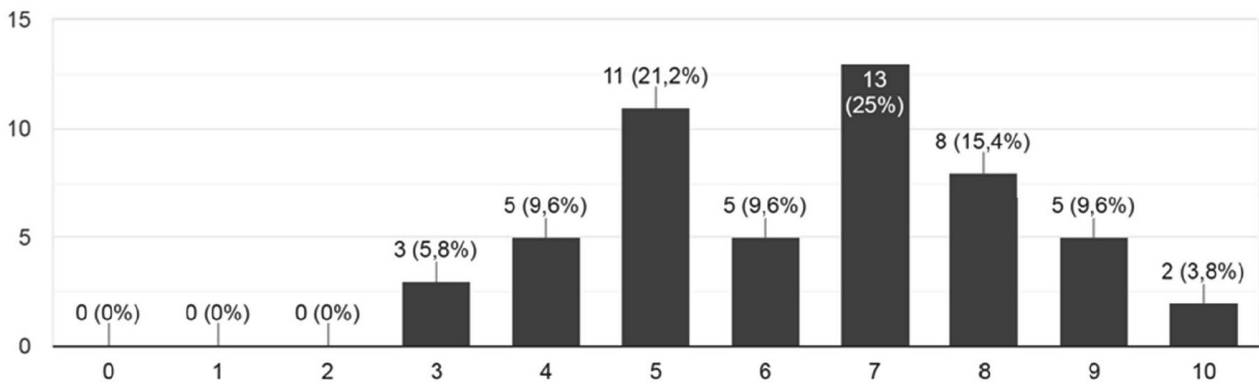

Figura 2. Grau de dificuldade na disciplina de QOI

Quadro 1. índices de aproveitamento por IES e professor, conforme matrícula em QOI

\begin{tabular}{|c|c|c|c|c|c|}
\hline $\begin{array}{c}\text { Universidade e } \\
\text { Professor de OQI }\end{array}$ & Aprovação & Reprovação & Infrequência & $\begin{array}{c}\text { Trancamentos ou } \\
\text { cancelamentos }\end{array}$ & $\begin{array}{c}\text { Total de matrículas } \\
\text { em QOI }\end{array}$ \\
\hline U1, P1 & $16(23,5 \%)$ & $32(47,1 \%)$ & $20(29,4 \%)$ & - & 68 \\
U1, P2 & $93(37,5 \%)$ & $88(35,5 \%)$ & $55(22,2 \%)$ & $12(4,8 \%)$ & 248 \\
U2, P1 & $40(43 \%)$ & $40(43 \%)$ & $8(8,6 \%)$ & $5(5,4 \%)$ & 93 \\
\hline
\end{tabular}

Fonte: autores, com base nos dados de registro docente das turmas. 
estudantes em disciplinas consideradas difíceis que são ofertadas nos primeiros semestres dos cursos como, por exemplo, Química Geral e Química Orgânica I. Nesse contexto, pesquisadores "salientam que as dificuldades encontradas pelos alunos levam a um alto índice de reprovação e quando a construção de saberes não é realizada, ao repetir a disciplina, muitas vezes, redunda na evasão do curso". ${ }^{50}$

Ao ingressarem no Ensino Superior, muitos discentes não estão preparados para o nível de dificuldade dos conceitos relacionados à QOI, pois mesmo depois da aprovação em Química Geral os estudantes apresentam dificuldades por não conseguirem relacionar os conceitos estudados com a QOI, para além do déficit na aprendizagem oriunda da Educação Básica. ${ }^{41}$ Sobre o impacto deste início do Curso Superior, de forma representativa, apresenta-se a reflexão de dois dos docentes que percebem dificuldades oriundas de uma problemática mais ampla, além da questão conceitual:

As disciplinas do primeiro semestre, apesar de tentar facilitar, são difíceis; mesmo com o grau de conhecimento que eles vêm. Eu tento suprir as deficiências do ensino médio. Eles chegam aqui e a evasão pega, porque eles não acompanham o ritmo: a maioria desiste. Eles já vêm com uma barreira psicológica, autoestima muito baixa, começam a ter depressão na Orgânica I. Eu tenho uns quantos atestados aqui de depressão, na Universidade (E-U1/P4/QOII).

Eles mudam de cidade, de estado; começam a ir mal e daí: ou eles desistem ou se arrastam até o final. Falta o lado psicológico para a aprendizagem e o Enem tá pegando uma pontuação mais baixa. O problema só vai se agravar (E-U1/ P6/QOII).

Essas posições docentes são reforçadas e encontram coerência com as pesquisas que indicam que estudantes, ao ingressarem no Ensino Superior, deparam-se com muitas mudanças importantes do estilo de estudo, grau de exigência, distância de familiares, apoio psicológico e/ou financeiro que demarcam este início da formação acadêmica dos graduandos, que também repercutem sobre seus rendimentos nas disciplinas basilares dos primeiros semestres. ${ }^{39,51,52}$ A partir do momento em que o estudante tem acesso a sua nota no ENEM, a escolha do Curso não é mais apenas por afinidade e sim por influência exclusiva da nota. ${ }^{53} \mathrm{~A}$ heterogeneidade na escolha dos graduandos é percebida nas respostas dos questionados de alguns dos estudantes. Ao escrever sobre o porquê da escolha do Curso emergem ideias como: "Gosto de ciências, mas prefiro Química do que Física" (Q-U2/QL5); “Nota de corte" (Q-U1/QL9); "Pensava em mudar de curso" (Q- U1/QB2).

A possibilidade de mudança de Curso também reporta para desestímulo à escolha do Curso. Na percepção de um dos docentes: "Outras dificuldades podem ter relação com o trampolim, né?! Os alunos às vezes usam os cursos, e na química acontece também. Entram em qualquer um, porque querem outra coisa" (E-U1/P5/ QOII). Desse modo, como a disciplina de QOI é de início de Curso, graduandos podem estar cursando QOI sem ter definido o Curso que desejam realizar, ou ainda acabam continuando o Curso sem ter a Química como primeira escolha, acarretando reprovação, infrequência, trancamento da disciplina e Curso.

Com o SISU, a mudança no perfil dos estudantes ingressantes nas Universidades é inevitável ${ }^{54}$ para docentes participantes desta pesquisa. A facilidade do ingresso unificado não trouxe benefícios como era esperado, conforme expressam alguns dos educadores:

A minha primeira turma de Orgânica ainda era remanescente do vestibular. Acho que foi uma das melhores turmas de Química Orgânica. Depois já vi que nas outras turmas sempre teve alunos bons, mas, na média, eles eram medianos ou fracos, principalmente nos últimos 3 anos. (E-U1/P5/QOII); $\mathrm{O}$ Enem democratizou o acesso às universidades, correto? $\mathrm{O}$ problema é que infelizmente o nivelamento está por baixo. O perfil mudou e eles estão chegando menos adultos, menos qualificados e eles não têm uma percepção de mundo. Eles não sabem nem porque estão aqui. (E-U1/P4/QOII)

A mudança foi e é significativa quando se passou a usar a nota do ENEM e a principal mudança está associada à falta de maturidade. Os alunos não precisam mais amadurecer, fazer suas escolhas e assumir seu protagonismo antes de ingressar na universidade. A facilidade de ingresso causa uma desvalorização da "conquista". (E-U2/P1/QOI).

O ENEM, em sua criação, em 1998 era utilizado apenas para avaliar o Ensino Médio. A partir de 2009 o ingresso em algumas universidades passou a ser mediante essa nota no SISU. Essa mudança no sistema de ingresso é defendida e criticada por alguns autores..$^{55,56}$ Nesse contexto, Silveira e colaboradores pontuam que a mobilidade dos estudantes para outras regiões é um ponto positivo podendo ingressar em instituições de ensino superior em outros estados..$^{57}$ Essa facilidade no ingresso provoca o aumento da evasão e retenção nos cursos, que pode ser causada pela falta de maturidade e facilidade no ingresso ou até mesmo devido a um baixo desempenho no ensino médio, que pode acarretar a um menor desempenho também nas IES. ${ }^{56}$ Assim como apontado na literatura, os docentes P4 e P5 também destacam questões ligadas ao ingresso unificado, com mudança relacionada ao perfil dos ingressantes, a exemplo da maturidade dos discentes e a desvalorização da conquista, conforme P1.

Ainda sobre o perfil dos ingressos, há grande destaque nas questões associadas com a deficiência conceitual, muito frisada nas falas docentes, como complementam P1 e P2:

Os discentes estão mais defasados em conhecimentos básicos e isso está ampliando a cada ano. (E-U2/P2/QOI)

Infelizmente, os alunos estão chegando na Universidade com um déficit de conhecimentos na Química. Na Orgânica I nem se fala! Eles não são capazes de reconhecer conceitos básicos. (E-U1/P1/QOI)

Como já anunciado na discussão sobre a deficiência conceitual, essa problemática acaba sendo levada à formação anterior, à educação básica - um recurso muito recorrente quando investigadas opiniões de docentes do Ensino Superior sobre as limitações ou dificuldades de aprendizagem de seus discentes. ${ }^{23}$ Ainda que essa seja uma noção problemática, pois encaminha para visões simplistas de um problema mais amplo, os professores retornam em seus discursos à dificuldade dos discentes com relação a conceitos básicos, havendo a percepção de que a cada ano os estudantes chegam com menor bagagem e profundidade de conceitos de Química. Logo, o ensino e a aprendizagem em QOI seriam afetados, pois estudantes não sabem e/ou reconhecem a linguagem, as explicações usadas pelos professores. Afinal, palavras, expressões e representações passam a não ter significado e sentido, não sendo compreendidas e interpretadas pelos discentes caso não sejam mediadas pelo professor, considerando conceitos anteriores, e isso dificulta relações fundamentais para a elaboração conceitual, como a relação entre linguagem e pensamento. ${ }^{22,58}$ Com base nos escritos dos professores que participaram da pesquisa, essas dificuldades em interpretar causam deficiências conceituais que se somatizam na formação profissional dos estudantes. Isso se deve também ao uso de conceitos abstratos e não intuitivos que merecem atenção por parte do professor, ${ }^{17}$ especialmente se as dificuldades conceituais são identificadas, como 
expresso pelos docentes investigados nesta pesquisa.

Segundo os discentes e docentes da UFPel e da Unipampa, os estudantes têm "facilidade" e "dificuldade" mais especificamente em alguns conceitos, como expresso no Quadro 2.

Ao comparar os conceitos que representam facilidade e dificuldade, tanto para os docentes quanto para os discentes, surgem conceitos comumente citados, como: Grupos funcionais, propriedades e nomenclatura, que indicados por alguns docentes e estão entre os considerados mais "fáceis" pelos estudantes.

Podemos observar que os docentes divergem em parte sobre suas posições a respeito dos conceitos que os estudantes têm facilidade e dificuldade. Todavia, no que se refere a maiores dificuldades, na explicação da resposta, docentes citam conceitos como mecanismos das reações, reatividade química e estereoquímica entre aqueles que eles dizem serem os de "maior dificuldade". O mesmo ocorre a conceitos que os estudantes alegam ter mais dificuldade. Os conceitos de mecanismos de reação são os mais mencionados como os de "maior dificuldade" para docentes e discentes, embora discentes destaquem a dificuldade em visualizar a molécula em $3 \mathrm{D}$, que tem relação direta com o conceito de estereoquímica, indicado por discentes, e que podem contribuir na compreensão de mecanismos e isomeria.

Diferentes pesquisadores apontam dificuldades de aprendizagem de Química Orgânica no Ensino Superior, com a existência de conteúdos que são vistos como mais difíceis de serem apreendidos. ${ }^{21,59}$ Estudantes universitários citam como conceitos "mais complexos" os estudos sobre: funções orgânicas; mecanismos; e estereoquímica. ${ }^{21}$ No caso das funções orgânicas, a dificuldade está relacionada ao método no qual o professor faz a apresentação da função, seguida da nomenclatura e das reações, e já passa para a função seguinte, sem que $\mathrm{o}$ aluno tenha tempo para identificar os grupos funcionais. ${ }^{21}$ Mariano e colaboradores ${ }^{60}$ salientam que a aprendizagem de mecanismos, por exemplo, é bastante complexa, pois os estudantes não sabem por onde começar. No caso da estereoquímica os estudantes também mostram dificuldades em entender a conformação e tridimensionalidade, porque precisam visualizar e manipular as estruturas químicas mentalmente em $3 \mathrm{D}$, sendo elas geralmente desenhadas ou projetadas em 2D, além da dificuldade com a contextualização do conteúdo. ${ }^{61}$

Os estudantes, ao serem questionados sobre o que é mais difícil de entender nas aulas de Química Orgânica, expressam frases como:
Não consigo visualizar, se muda muito o formato e os mecanismos (Q- U2/QL9);

Todo o conteúdo que envolve mecanismos de reação (Q-U1/ QB3);

Alguns conceitos e mecanismos de reação (Q-U1/F2);

Acredito que a disciplina é bem difícil. Compreender os mecanismos é algo que, para mim, foi complicado (Q- U1/ QI1);

A didática de alguns professores é bastante confusa. Não entendo mecanismos (Q-U2/QL5).

As respostas não são muito explicativas, mas indicam um dos conteúdos (mecanismos de reação) que perpassa grande parte da disciplina, o que repercute em resultados de avaliações e no (in) sucesso na QOI. De acordo com Mariano e colaboradores:

O ensino dos mecanismos de reações em disciplinas de Química Orgânica para alunos dos cursos de graduação e pós-graduação em Química ainda representa um desafio. De certa forma, as idéias dos alunos sobre reações orgânicas estão relacionadas à "intuição química" e refletem um conhecimento compartimentalizado. O entendimento de uma reação química envolve conceitos microscópicos (em nível molecular) e macroscópicos (coleção de muitas moléculas) dos sistemas químicos investigados (reagentes, estados de transição e produtos) e o que se espera é que o aluno consiga correlacionar estes conceitos. ${ }^{60}$

Além dos mecanismos, amplamente mencionados pelos graduandos, o conceito de Estereoquímica está entre os conceitos considerados complexos em QOI por docentes e discentes, como exposto no Quadro 2. Essas dificuldades podem ser atribuídas principalmente ao momento de imaginar a visualização das estruturas e suas conformações espaciais. ${ }^{62}$ Outra dificuldade encontrada no ensino de estereoquímica emerge a partir da utilização de representações, pois não é possível explicar tais conceitos por meio de fórmulas estruturais planas; afinal, algumas características dependem da estrutura tridimensional da molécula. ${ }^{60}$

Durante as aulas normalmente as estruturas químicas são desenhadas no quadro e/ou usadas em projeção em diapositivos, como

Quadro 2. Conceitos que representam facilidade e dificuldade, segundo professores de QOI e QOII e os graduandos de QOI

\begin{tabular}{|c|c|c|}
\hline Universidade/ Professor & Facilidade & Dificuldade \\
\hline U1/P5/QOII & Reações de substituições nucleofílicas. & Nomenclatura básica, grupos funcionais, e mecanismos. \\
\hline U1/P4/QOII & $\begin{array}{l}\text { Nomenclatura; cadeias carbônicas; carbono primário, } \\
\text { secundário, terciário e função orgânica; propriedades físicas } \\
\text { e químicas; pontos de ebulição e fusão, e densidade. }\end{array}$ & $\begin{array}{l}\text { Química quântica, hibridização, aspecto tridimensional da } \\
\text { molécula, mecanismos, reatividade, e estereoquímica. }\end{array}$ \\
\hline $\mathrm{U} 1 / \mathrm{P} 1 / \mathrm{QOI}$ & Aromaticidade e substituição eletrofílica aromática. & $\begin{array}{l}\text { Principais funções orgânicas; Mecanismos. Efeitos eletrôni- } \\
\text { cos de indução e ressonância. }\end{array}$ \\
\hline $\mathrm{U} 2 / \mathrm{P} 1 / \mathrm{QOI}$ & Nomenclatura. & $\begin{array}{l}\text { Conceitos de acidez, basicidade, eletrofilicidade, nucleofili- } \\
\text { cidade, e reatividade. }\end{array}$ \\
\hline $\mathrm{U} 2 / \mathrm{P} 2 / \mathrm{QOI}$ & Relata que não há facilidade em nada. & $\begin{array}{c}\text { Diferença de eletronegatividade entre os átomos e qual a } \\
\text { interferência no tipo de espécie reativa poderia ser formada, } \\
\text { polaridade, solubilidade, forças intermoleculares, e reativi- } \\
\text { dade química. }\end{array}$ \\
\hline U1/P3/QOII & $\begin{array}{c}\text { Não cita conceitos específicos relacionados à Química } \\
\text { Orgânica. }\end{array}$ & $\begin{array}{c}\text { Não cita conceitos específicos relacionados à Química } \\
\text { Orgânica. }\end{array}$ \\
\hline Estudantes & $\begin{array}{l}\text { Grupos Funcionais, estrutura dos compostos orgânicos, } \\
\text { nomenclatura, e propriedades físicas. }\end{array}$ & $\begin{array}{c}\text { Estereoquímica, adição eletrofílica, isomeria, reatividade, } \\
\text { mecanismo, e reatividade. }\end{array}$ \\
\hline
\end{tabular}

Fonte: Registros dos Autores (2020). 
se observou em diário de bordo (DB-U2/QOI). Durante a observação das aulas foi possível perceber que entre as dificuldades dos estudantes está principalmente a de imaginar como as moléculas podem ser representadas, no movimento e nas conformações que as partículas químicas podem assumir, tendo como base o material em slides oferecido pelo professor (DB-U2/QOI). Essas dificuldades também podem estar associadas com deficiências conceituais em conceitos mais básicos da Química, tais como compreensão de propriedades periódicas (a exemplo de eletronegatividade) e geometria (relacionada à capacidade de manipular, movimentar e imaginar de maneira tridimensional as moléculas), ${ }^{27}$ dentre outras que serão importantes para o entendimento dos mecanismos de uma reação química. No que tange à geometria, é bastante comum evidenciar que nas aulas de QOI, quase sempre, se tem uma abordagem que não valoriza a utilização de metodologias que possam facilitar a visualização em 3D. ${ }^{63}$

Segundo Kumi e colaboradores ${ }^{63}$ as representações bidimensionais, que normalmente são utilizadas em aulas e em livros didáticos, ajudam os estudantes a entender de maneira conceitual a molécula estudada, mas pouco possibilitam ao estudante perceber as diferenças entre as moléculas, uma vez que podem se diferir na posição tridimensional. Nesse contexto, é importante buscar recursos que possam ser utilizados na aprendizagem de conceitos químicos que necessitem representações tridimensionais. Pesquisadores salientam que recursos virtuais deixam as representações mais flexíveis, podendo convertê-las de 2D para representações que simulam $3 \mathrm{D}$ e vice-versa. Além desses recursos, também podem ser utilizados, por exemplo, modelos moleculares que ajudam os estudantes nesse processo de visualização das moléculas de maneira espacial e tridimensional. ${ }^{17,64}$

O insucesso escolar dos acadêmicos em componentes curriculares relacionados à Química, entre eles a QOI, expressa a dificuldade na apropriação dos conhecimentos ensinados, fatores esses que levam ao aumento da retenção e evasão nos cursos relacionados à Química das IES brasileiras. ${ }^{50,65}$ Para Cruz, assim como estudantes encontram obstáculos no processo de aprendizagem, os professores também têm obstáculos no processo de ensinar. ${ }^{66}$ Quadros e Mortimer, ${ }^{8}$ por exemplo, frisam que os docentes do Ensino Superior muitas vezes estão preocupados somente com o conhecimento específico da sua área de formação, apresentando dificuldades em ensinar alguns conceitos Químicos.

Ao considerar o contexto em estudo, é necessário pensar que as dificuldades não estão atreladas somente aos docentes, à sua didática, ou aos discentes, à sua automomia para o desenvolvimento de seu estudo. Afinal, a dificuldade associada à QOI, ao processo de ensino e de aprendizagem, é permeada de questões, como lacunas conceituais oriundas da Educação Básica, o sistema de ingresso no Ensino Superior, as necessárias relações conceituais de conteúdos que demandam, por exemplo, habilidades visuespaciais, ao perfil discente e a importância de dar maior suporte aos discentes (que enfrentam mudanças de esfera econômica, cultural) etc. Tais elementos marcam um cenário que merece atenção e novos estudos, a exemplo de melhores compreensões sobre como se estabelecem os processos de elaboração conceitual de conteúdos em sala de aula, a exemplo daqueles citados como de maior dificuldade, e sobre aspectos históricos e sociais que envolvem estudantes e professores do Ensino Superior.

\section{CONSIDERAÇÕES FINAIS}

A literatura aponta algumas preocupações da área da Educação Química na busca da qualificação dos processos de ensino e de aprendizagem em diferentes níveis de ensino, haja vista que o processo de elaboração de conceitos químicos demanda processos complexos de ensino. Das várias discussões, destacam-se dificuldades na articulação de elementos conceituais da química com o cotidiano. Como efeitos, nota-se que tais limitações têm implicações na aprendizagem dessa área e na sua compreensão, mobilização e utilização pelos sujeitos que passam pelos processos escolares. Desse modo, minimizar essas dificuldades e limitações é uma tarefa comum à comunidade da Educação Química e das demais áreas que compõem essa ciência.

O levantamento do contexto das duas Universidades e Cursos de Química permitiu evidenciar algumas semelhanças e diferenças em termos de conteúdos trabalhados, metodologias usadas pelos professores, pré-requisitos e semelhanças no perfil dos estudantes. $\mathrm{Na}$ análise dos dados foi possível perceber que os índices de reprovação em QOI apresentam índices superiores à soma das infrequências e reprovações, independente do professor ou da Universidade investigada. Desse modo, uma das contribuições do presente estudo, ainda que limitado ao contexto de sua realização, evidencia que a oferta da QOI na forma de turma mista (para mais de um curso), turma ofertada apenas para um Curso, a mudança de professor, de universidade, etc. não implicaram em resultados muito distintos no aproveitamento dos graduandos. Isso permite que se emerjam problematizações e discussões sobre os processos de ensino e de aprendizagem já consolidados no ensino dessa disciplina, suas abordagens e recortes conceituais. Tal encaminhamento se dá no sentido de possibilitar rever metodologias utilizadas atualmente em turmas de QOI, a fim de buscar minimizar as dificuldades associadas ao desempenho acadêmico. A outra contribuição desta pesquisa está vinculada à relação entre a disciplina e seu contexto mais amplo de formação, o que sugere a importância de rever e/ou buscar mecanismos de melhor inserção e permanência na Universidade, para acolher os estudantes e assim diminuir as taxas de evasão e retenção dos Cursos de Química.

Ao analisar o contexto das duas IES, apresentar resultados e incentivar problematizações no campo do Ensino de Química, este texto busca contribuir para a discussão sobre dificuldades de ensino e de aprendizagem em Química, especialmente em Química Orgânica do Ensino Superior. Ainda que quimérica e sempre incompleta a tarefa do educar(-se) e do formar(-se), intentar isso nos move a cada vez mais e melhor pensar, produzir e reconstruir o Ensino de Química e sua contribuição com a formação dos sujeitos.

\section{MATERIAL SUPLEMENTAR}

As questões realizadas com graduandos que estavam cursando ou que cursaram Química Orgânica I (S1) e aquelas realizadas com professores de Química Orgânica I e II (S2), das duas IES investigadas, constam no documento suplementar em apêndice a este texto e com acesso livre a partir do website da revista Química Nova (http://quimicanova.sbq.org.br/).

\section{REFERÊNCIAS}

1. Pastoriza, B. S.; Sangiogo, F. A.; Bosenbecker, V. K. Em Reflexões e Debates em Educação Química: ações, inovações e políticas; Pastoriza, B. S., Sangiogo; F. A., Bosembecker, V. K., org.; CRV: Curitiba, 2017.

2. Zucco, C. A.; Quim. Nova 2011, 34, 734.

3. Reis, R. da S.; Leite, B. S.; Leão, M. B. C.; Revista Debate e Educação 2019, 23, 1 .

4. Silveira, R. M.; Bazzo, W.; VI Encontro Nacional de Pesquisa em Educação em Ciências. Florianópolis, Brasil, 2007.

5. Maceno, N. G.; Guimarães, O. M.; Quim. Nova Esc. 2013, 35, 48.

6. Finger, I.; Bedin, E. A.; Revista Brasileira de Ensino de Ciências e Matemática 2019, 2, 24.

7. Ensino de química em foco; Santos, W., Maldaner, O., orgs.; Unijuí: Ijuí, 2010. 
8. Quadros, A. L.; Mortimer, E. F.; Quim. Nova 2016, 39, 640.

9. Jesus, F. P.; Debates em Educação 2015, 7, 15.

10. Chassot. A.; Para que (em) é útil o ensino?, $2^{\mathrm{a}}$ ed., Ulbra: Canoas, 2004.

11. Rebelo, J. A. S.; Dificuldades da leitura e da escrita em alunos do ensino básico, $1^{\text {a }}$ ed., Rio Tinto: Edições Asa. 1993.

12. Schnetzler, R. P. A.; Quim. Nova 2002, 25, 24.

13. Zanon, L. B; Maldaner, O. A. Em Ensino de Química em Foco; Santos, W. L., Maldaner, O. A., orgs.; Ijuí: Unijuí, 2010.

14. Raupp, D.; Serrano, A.; Moreira, M.; Revista Experiências em Estudo de Ciências 2009, 4, 78.

15. Akçayir, G.; Akçayir, M.; Computers \& Education 2018, 126, 345.

16. Pereira, J. A.; Silva Junior, J. F.; Silva, E. V.; Revista Debates em Ensino de Química 2019, 5, 131.

17. da Silva, A. M.; Revista de Química Industrial 2011, 731, 12.

18. Roque, N. F.; Silva, J. L. P. B.; Quim. Nova 2008, 31, 923.

19. Daitx, A. C.; Loguercio, R. Q; Strack, R.; Investigações em Ensino de Ciências 2016, 21, 178 .

20. Maximiano, F. A.; Estudos Avançados 2018, 32, 245.

21. Belinaso, J.; Silva, S. M.; Eichler, M. L.; Salgado, T. D. M.; Pino, J. C. D.; VII Enpec, 2009.

22. Mortimer, E. F. Linguagem e formação de conceitos no Ensino de Ciências. Editora UFMG: Belo Horizonte, 2000, 383 p.

23. Alvarenga, C. F.; Sales, A. P.; Revista Pensamento Contemporâneo em Administração 2012, 6, 71.

24. Massi, L.; Santos, G.; Ferreira, J.; Queiroz, S. L.; Quim. Nova 2009, 32, 503.

25. Silva, A. C. C.; Batalini, C.; Revista Panorâmica Online 2020, 3, 47.

26. Silva, M. G. L.; Silva, A. F; Núñez, I. B. Em Fundamentos do ensino aprendizagem das Ciências Naturais e da Matemática: o novo ensino médio; Nuñez, I. B., Ramalho, B. L., orgs.; Sulina: Porto Alegre, 2004.

27. Raupp, D. T.; Tese de Doutorado, Universidade Federal do Rio Grande do Sul, Brasil, 2015.

28. Lima, T. C. S.; Mioto, R. C. T.; Dal Prá, K. R..; Revista Textos \& Contextos 2007, 6, 104.

29. Bardin, L.; Análise de Conteúdo; Reto, L. A., Pinheiro, A., trad.; $1^{\mathrm{a}}$ ed., Martins Fontes: São Paulo, 1977.

30. Moraes, R.; Revista Educação 1999, 22, 7.

31. Gil, A. C.; Metodologia do ensino superior, $4^{\mathrm{a}}$ ed., Atlas: São Paulo, 2011.

32. Lüdke, M.; André, M. E. D. A.; Pesquisa em educação: abordagens qualitativas, EPU: São Paulo, 1986.

33. Yin, R. K.; Estudo de caso: Planejamento e métodos, Bookman: Porto Alegre, 2001.

34. Stake, R. E.; The art of case study research, SAGE Publications: London, 1995.

35. Projeto Pedagógico do Curso Licenciatura em Química da Universidade Federal de Pelotas, UFPel: Pelotas, 2016

36. Projeto Pedagógico do Curso de Química Licenciatura da Universidade Federal do Pampa - Campus Bagé, UNIPAMPA, 2016.

37. Ferreira, M.; Del Pino, J. C.; Acta Scientiae 2009, 11, 101.

38. Arruda, S. de M.; Carvalho, M. A.; Passos, M.; Silveira, F.; Caderno Brasileiro de Ensino de Física 2006, 23, 217.

39. Pereira, A.; Carneiro, T. C. J.; Brasil, G. H.; Corassa, M. A. de C.; Ensaio: aval. pol. públ. Educ. 2015, 23, 1039.
40. Halfen, R.; Nachtigall, S. B.; Merlo, A.; Raupp, D. T.; Revista Electrónica de Enseñanza de las Ciencias 2020, 19, 270.

41. Batista, B. M.; Vascocellos, P. S.; Passos, C. G.; Pazinato, M. S.; Research, Society and Development 2020, 9, 23.

42. Schenetzler, R. P.; Aragão, R.; Quim. Nova Esc. 1995, 1, 27.

43. de Oliveira, C.; Pedagogia em Ação 2015, 7, 1.

44. Matta, C. M. B. da.; Lebrão, S. M. G.; Heleno, M. G. V.; Psicologia Escolar e Educacional 2007, 21, 591.

45. Carvalho, P. S.; Dissertação de Mestrado, Universidade Fernando Pessoa, Portugal, 2012.

46. Valadão, D. L.; Araujo Neto, W. N.; Lopes, J. G. S.; Anais do XI Encontro Nacional de Pesquisa em Educação em Ciências, Florianópolis, Brasil, 2017.

47. Lima, E. G. dos S.; Malange, F. C. V; Borges, L. F.; Acta Scientiarum. Education 2018, 40, 13.

48. INEP; Censo da Educação Superior: Resumo Técnico, 2016, disponível em: http://download.inep.gov.br/educacao_superior/censo_superior/ resumo_tecnico/resumo_tecnico_censo_da_educacao_superior_2016. pdf, acessado em janeiro 2021.

49. Yamaguchi, K. L; Silva, J. da Silva E.; Quim. Nova 2019, 42, 354.

50. Silva, R. R.; Tunes, E.; Pachá, L. C. L.; Junqueira, R. M. P.; Quim Nova 1995, 18, 214.

51. Nogueira, M. J.; Sequeira, C.; Revista Portuguesa de Enfermagem de Saúde Mental 2017, 5, 56.

52. Teixeira, M. A. P.; Dias, A. C. G.; Wottrich, S. H.; Revista Quadrimestral da Associação Brasileira de Psicologia Escolar e Educacional 2008, 19, 185.

53. Melo, K. C.; Dissertação de Mestrado, Universidade Federal do Rio Grande do Norte, Natal, Brasil, 2017.

54. Heringer, R.; Revista Brasileira de Orientação Profissional 2018, 19, 17.

55. Sousa, S. C.; Gonçalves, R. M. L.; Souza, G. H. D.; Evidência 2017, 13, 113.

56. Barros, A. S. X.; Ensaio: aval. pol. públ. Educ. 2014, 22, 1090.

57. Silveira, F. L.; Barmosa, M. C. B.; Silva, R.; Revista Brasileira de Ensino de Física 2015, 37, 1101-5.

58. Vigotski, L. S.; Luria, A. R.; Leontiev, A. N.; Linguagem, desenvolvimento e aprendizagem, $7^{\mathrm{a}}$ ed., Ícone: São Paulo, 2001.

59. Halford, B.; Chemical and Engineering News 2016, 94, 27.

60. Mariano, A.; Ventura, E.; Monte, S. A.; Braga, C. F.; Carvalho, A. B.; Araujo, R. C. M. U.; Santana, O. L.; Quim. Nova 2008, 31, 1243.

61. Baker, R. W.; George, A.V. E.; Harding, M. M.; J. Chem. Educ. 1998, $75,853$.

62. Raupp, D. T.; Dissertação de Mestrado, Universidade Luterana do Brasil, Brasil, 2010.

63. Kumi, B. C.; Olimpo, J. T.; Bartletta, F.; Dixon B. L.; Chem. Educ. Res. Prato. 2013, 14, 187.

64. Hofer, B. K.; Pintrich, P. R.; Review of Educational Research 1997, 67, 140.

65. Silva Filho, R. L. L.; Motejunas, P. R.; Hipolito, O.; Lobo, M. B. de C. M.; Cadernos de Pesquisa 2007, 37, 659.

66. Cruz, J. M. O.; Educação \& Sociedade 2008, 29, 1043. 